\title{
Aspectual asymmetries in the mental representation of events: Role of lexical and grammatical aspect
}

\author{
Foong Ha Yap, Patrick Chun Kau Chu, Emily Sze Man Yiu, and Stella Fay Wong \\ Chinese University of Hong Kong, Hong Kong, China
}

\author{
Stella Wing Man Kwan, Stephen Matthews, and Li Hai Tan \\ University of Hong Kong, Hong Kong, China \\ PING LI \\ National Science Foundation, Arlington, Virginia \\ and Pennsylvania State University, University Park, Pennsylvania
}

AND

\author{
YASUHIRO SHIRAI \\ University of Pittsburgh, Pittsburgh, Pennsylvania
}

\begin{abstract}
Temporal information is important in the construction of situation models, and many languages make use of perfective and imperfective aspect markers to distinguish between completed situations (e.g., He made a cake) and ongoing situations (e.g., He is making a cake). Previous studies in which the effect of grammatical aspect has been examined have shown that perfective sentences are often processed more quickly than imperfective ones (e.g., Chan, Yap, Shirai, \& Matthews, 2004; Madden \& Zwaan, 2003; Yap et al., 2004; Yap et al., 2006). However, these studies used only accomplishment verbs (i.e., verbs with an inherent endpoint, such as bake a cake). The present study on the processing of Cantonese includes activity verbs (i.e., durative verbs with no inherent endpoint, such as play the piano), and the results indicate a strong interaction between lexical aspect (i.e., verb type) and grammatical aspect. That is, perfective sentences were processed more quickly with accomplishment verbs, consistent with previous findings, but imperfective sentences were processed more quickly with activity verbs. We suggest that these different aspectual asymmetries emerge as a result of the inherent associations between accomplishment verbs and the bounded features of perfective aspect and between activity verbs and the unbounded features of imperfective aspect. The sentence stimuli from this study may be downloaded from mc.psychonomic-journals.org/content/supplemental.
\end{abstract}

We construct situation models as we listen to narratives, using various cues such as temporal and spatial information, agent intentionality, and causality, among many others (e.g., Ferretti, Kutas, \& McRae, 2007; Morrow, 1985, 1990; Zwaan \& Radvansky, 1998). With respect to temporal information, aspectual cues (e.g., the -ed vs. -ing contrast in sentences such as She knitted a sweater vs. She was knitting a sweater) are known to play a very important role in cognitive representations (e.g., Carreiras, Carriedo, Alonso, \& Fernández, 1997; Givón, 1992; Hopper, 1979; Magliano \& Schleich, 2000). However, previous processing studies have not always clearly distinguished between lexical and grammatical aspect. In the present study, we will highlight their differences and examine how they interact in the course of sentence processing.

\section{Two Types of Aspect}

Aspect refers to different ways of viewing the temporal characteristics of a situation (Comrie, 1976). There are two major types of aspect: lexical and grammatical aspect. Lexical aspect refers to situation types denoted in the verb (phrase) that are distinguished on the basis of temporal properties, such as dynamism, durativity, and telicity. Dynamism contrasts with stativity and is defined in terms of whether or not energy is needed to maintain a given situation. Durativity contrasts with instantaneity and is defined in terms of how long or how briefly a situation persists. Telicity is defined in terms of whether an event involves a natural endpoint. If a verb is not telic, it is atelic.

Vendler (1967) distinguished four major lexical aspect categories, or verb types, which can be defined with these three features (see Table 1). A stative verb (e.g., love) de-

F. H.Yap, foong_ha_yap@cuhk.edu.hk 
Table 1

Verb Types and Their Temporal Properties (Adapted From Andersen, 1991)

\begin{tabular}{lcccl}
\hline \multicolumn{1}{c}{ Verb Type } & Dynamic & Telic & Punctual & Example \\
\hline State & - & - & - & know \\
Activity & + & - & - & play \\
Accomplishment & + & + & - & run a mile \\
Achievement & + & + & + & break \\
\hline
\end{tabular}

scribes a nondynamic situation that is viewed as continuing to exist unless some external force makes it change. An activity verb (e.g., run) describes a dynamic and durative situation that has an arbitrary endpoint (i.e., it can be terminated at any time). In contrast, an accomplishment verb (e.g., make a chair) describes a situation that is dynamic and durative but has a natural endpoint involving a change of state, after which the particular action cannot continue. Finally, an achievement verb (e.g., die) describes a situation that can be reduced to a point on a time axis (i.e., it is instantaneous and punctual).

Grammatical aspect refers to grammaticalized linguistic devices, often in the form of inflections and/or auxiliaries (e.g., English -ed and be + V-ing), that allow the speaker to impose a bounded or unbounded perspective on a situation or event (hence, the term viewpoint aspect as well; see Smith, 1997). Such bounded versus unbounded distinction is typically discussed in terms of perfective versus imperfective grammatical aspect. In simple terms, perfective aspect denotes completed events, whereas imperfective aspect denotes ongoing situations. As defined in Comrie (1976), perfective aspect allows us to view an event as a completed whole (bounded or external perspective), whereas imperfective aspect constrains us to focus on the internal stages of an ongoing situation (unbounded or internal perspective). For example, in English, the progressive form (be $+\mathrm{V}$-ing) marks imperfective aspect, whereas the simple past form (V-ed, as well as other irregular past forms) marks perfective aspect.

\section{Processing Asymmetries}

A number of recent studies have shown the effects of grammatical aspect on processing. Magliano and Schleich (2000) showed that imperfectives yield slower decay rates in sentence recognition tasks. In their study, participants were asked to read English passages and to subsequently decide whether target verb phrases (either perfective or imperfective) appeared in those narratives. The results showed that the participants responded significantly more quickly to imperfective versions than to perfective ones. The shorter recognition time for imperfective verbs was attributed to their slower decay rate, which allows for longer activation and retention in working memory.

Ferretti et al. (2007) also found asymmetrical effects of grammatical aspect in an elicitation task in which participants were asked to complete sentence fragments containing either perfective verb phrases (using past perfect; e.g., The cow had grazed __ ) or imperfective verb phrases (using past progressive; e.g., The cow was grazing __ ). The participants produced more locative prepositional phrases (e.g., in the meadows) for imperfective sentence fragments, as compared with perfective ones. For perfective sentence fragments, the participants tended to produce other types of prepositional phrases (e.g., in the evening) or noun phrases that identified affected patients (e.g., itself) rather than locations. In other words, the participants appeared to be sensitive to event knowledge; that is, they tended to associate ongoing events (marked by imperfective aspect) with locative prepositional phrases and completed events (marked by perfective aspect) with noun phrases denoting affected entities.

Furthermore, in a comprehension task using ERP measures, Ferretti et al. (2007) found that atypical locations (e.g., cook in the museum) elicited a higher N400 amplitude than did typical locations (e.g., cook in the kitchen) for events denoted by verbs marked with imperfective aspect (e.g., was cooking). For verbs marked with perfective aspect (e.g., had cooked), no significant difference in N400 amplitude was found for expectancy of locations for the event. These results likewise indicate that participants are more sensitive to subtle differences in locative interpretations when processing imperfective sentences, but not perfective ones. This is consistent with our understanding that imperfective sentences highlight the internal and unbounded view of an event (inclusive of its locative details), whereas perfective sentences highlight an external and bounded view that pays more attention to result or patient affectedness than to locus of action.

Asymmetrical effects of grammatical aspect on sentence processing have also been reported in Madden and Zwaan (2003). Using a series of sentence-picture matching tasks, they found that participants were significantly faster in matching perfective sentences (e.g., He made a fire) with pictures depicting completed situations, as opposed to pictures depicting ongoing situations. In contrast, when participants were shown sentences with imperfective aspect (e.g., He was making a fire), no significant difference was found between their response times (RTs) to ongoing pictures and completed pictures. Madden and Zwaan's findings suggest that perfective sentences are more quickly matched to completed than to ongoing pictures because it is easier to converge on a mental representation of events with a clear endpoint focus.

The findings from these previous studies thus clearly show that aspectual asymmetry in sentence processing is fairly common. As was reported in Magliano and Schleich (2000), imperfective aspect imposes an ongoing perspective for events, enhancing their retention in active working memory, whereas perfective aspect, with its terminative (or bounded) focus, yields a shorter retention rate, with activation of the events in working memory decaying much more quickly. It is thus not surprising that perfective sentences are typically used to foreground and rapidly advance a story plot, whereas imperfective sentences are frequently used as specificational or backgrounding information in narratives to enhance text cohesion (Hopper, 1979). As was noted in Ferretti et al. (2007), imperfective sentences focus on the locus of ongoing action, whereas perfective sentences focus on the end result for an affected patient. Madden and Zwaan (2003) showed that choice of grammatical aspect (perfective vs. imperfective) can 
yield different asymmetry patterns in processing speeds. In sum, these studies indicate that grammatical aspect contributes to our mental model of a situation in complex and often asymmetrical ways.

\section{Perfective Facilitation}

Madden and Zwaan's (2003) participants matched perfective sentences with pictures depicting completed events more quickly than they matched them with pictures depicting ongoing events; however, no speed bias was observed for imperfective sentences in similar conditions. This finding points to a facilitative effect from perfectives, but not imperfectives, which we call perfective facilitation.

Perfective facilitation has also been found in other languages. In a similar sentence-picture matching task with native Cantonese speakers, aspectual asymmetry in processing was manifested as follows: Sentences with perfective $z o 2$ in Cantonese ${ }^{1}$ were processed significantly more quickly than those with imperfective progressive gan 2 (Chan, Yap, Shirai, \& Matthews, 2004). ${ }^{2}$

Similar results were also found in Mandarin, where sentences with perfective $l e$ were processed significantly more quickly than those with imperfective progressive zai (Yap et al., 2004). A similar study on Japanese likewise showed that sentences with perfective - $t a$ were processed more quickly than those with imperfective -teiru (Yap et al., 2006).

It is important to note that in all these studies, the verbs used to test the effect of grammatical aspect (perfective vs. imperfective) were accomplishment verbs (e.g., make a fire), and the role of lexical aspect itself (e.g., accomplishment vs. activity) was not independently evaluated. It is well known that, crosslinguistically, there is a strong interaction between lexical and grammatical aspect in both acquisition and use of aspectual marking (e.g., Comrie, 1976; Li \& Shirai, 2000). Research has shown that in terms of use, telic verbs (i.e., verbs with an inherent endpoint focus, such as accomplishments) are more frequently used with perfective aspect, whereas atelic verbs (including activities) are more often used with imperfective aspect, and that in acquisition, perfective markings are acquired earlier with telic verbs, whereas imperfective markings are acquired earlier with atelic verbs (Andersen \& Shirai, 1996). It is thus possible that use of different verb types may yield different results in sentenceprocessing studies - for example, perfective facilitation may not predominate for atelic verbs.

In this study, we investigated the effect of both lexical aspect and grammatical aspect on sentence processing and picture matching by examining whether perfective facilitation would hold across different verb types. In particular, we extended our study to activity verbs.

\section{Temporal Reference System of Cantonese}

Our study focused on Cantonese, a Chinese language spoken in the southern part of China. As is typical of Chinese languages, Cantonese lacks grammaticalized tense but is rich in aspectual marking. Temporal reference is inferred from information provided through temporal ad- verbs (e.g., kam4jat6 "yesterday," ji4gaal "now," tingljat6 "tomorrow"), lexical aspect, and grammatical aspect markers, as well as pragmatic context (Matthews \& Yip, 1994).

In terms of grammatical aspect, Cantonese is known to have a wide range of both perfective and imperfective aspect markers (Matthews \& Yip, 1994). Included within the perfective inventory are the completive marker jyun4, the perfective marker $z o 2$, and the experiential marker gwo3. Included within the imperfective inventory are the locative/progressive marker hai2dou6, the progressive marker gan 2 , the durative marker zyu6, and the continuative marker hoil. Scholars generally agree that perfective zo2 and imperfective progressive gan 2 are among the most versatile grammatical aspect markers in Cantonese-in that they can be attached to a wide range of verbs in the language (Chor, 2004, p. 39; see also p. 58).

Perfective zo 2 draws attention to the relevance of a completed action to a subsequent time frame that often involves the present (e.g., ngo5 sik6 zo2 faan6 "I have eaten," with the possible implication that the speaker is no longer hungry and will not be joining the addressee for dinner). Imperfective gan2 highlights the ongoingness of an action, similar to English progressive -ing (e.g., ngo5 sik6 gan2 faan6 "I am [in the midst of] eating rice/a meal").

The present study focused on the perfective aspect marker $z o 2$ and the imperfective (progressive) aspect marker gan2. Analyzing this pair of contrastive aspect markers would help us to better understand the nature of aspectual asymmetries in language processing, particularly in tenseless languages. One important reason for examining languages without obligatory tense marking was that we could conveniently avoid problems related to tense-aspect conflation (often seen in English). To illustrate, Cantonese sentences such as ngo 5 sik6 zo2 faan 6 ("I eat rice already") versus ngo5 sik6 gan2 faan6 ("I eating rice") provide a clear contrast between perfective and imperfective aspect, whereas English sentences such as I've eaten rice versus I was eating rice yield not only perfective/imperfective aspectual contrast, but also past/ present deictic distinctions, which opens up more complex permutations than does the much simpler two-way aspectual contrast found in Cantonese. In other words, by focusing on Cantonese aspect markers, we were in a better position to investigate aspectual asymmetry phenomena.

\section{Research Questions and Hypotheses}

The research questions were as follows. Does lexical aspect interact with grammatical aspect to influence processing speed? And if so, how? More specifically, do accomplishment and activity verbs yield different aspectual facilitation patterns in a sentence-picture matching task? We hypothesized faster perfective processing for accomplishment verbs but faster imperfective processing for activity verbs. This prediction was based on the findings of previous studies in language acquisition and use, both of which showed strong associations between accomplishment verbs and perfective aspect markers and between activity verbs and imperfective progressive aspect markers (e.g., Andersen \& Shirai, 1994, 1996; Li \& Shirai, 2000; Shirai \& Andersen, 1995). 


\section{THE STUDY}

In this study, we investigated the effects of both lexical aspect and grammatical aspect on language processing in Cantonese. With respect to lexical aspect, we compared native speakers' RTs in processing different types of verbs - more specifically, accomplishments versus activities. As is noted in Table 1, accomplishment verbs are dynamic, durative, and telic (i.e., bound by an inherent endpoint), whereas activity verbs are dynamic and durative but atelic (i.e., without an inherent endpoint). Examples (in romanized Cantonese) are shown in (1) and (2) below. ${ }^{3}$ $\mathrm{ACC}$ and ACT are abbreviations for accomplishment and activity verbs, respectively. CL stands for classifier; languages such as Cantonese make frequent use of classifiers to instantiate nominal referents.

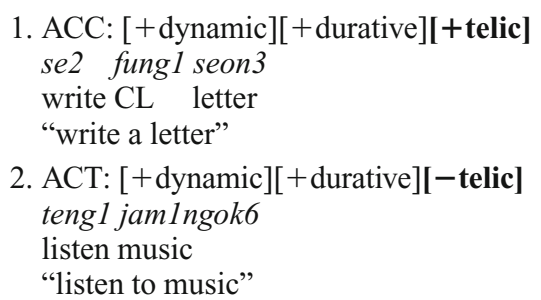

With respect to grammatical aspect markers, we examine the effects of imperfective marker gan 2 and perfective marker zo2. Gan2 denotes a progressive sense, as in (3). $Z o 2$, on the other hand, induces a completive sense. It highlights the relevance of a completed event to a subsequent or later situation (much like the English perfect have + V-en), as in (4). In the English glosses in (3) and (4) below, IMPF and PERF are abbreviations for imperfective and perfective aspect markers, respectively.

\section{Imperfective gan 2 \\ go3 naam4zai 2 jau4-gan2 seoi 2 \\ CL boy swim-IMPF water \\ "The boy is swimming." \\ 4. Perfective zo2 \\ go3 naam4zai2 jau4-zo2 seoi2 \\ CL boy swim-PERF water \\ "The boy has finished swimming."}

\section{Method}

Participants. Eighty-three native speakers of Cantonese at Grade 12 in three local secondary schools in Hong Kong took part in this experiment (mean age $=18$ years).

Materials. Forty Cantonese sentences were constructed for the experiment proper: 20 sentences depicting activity events and 20 sentences depicting accomplishment events. Each event depicted in the experimental sentences was described with either imperfective marker gan 2 or perfective marker zo2 (e.g., Maa4maal guk6 gan2 go3 daan6goul "Mother is baking a cake" vs. Maa4maal guk6 zo2 go3 daan6goul "Mother has baked a cake"). Both aspect markersimperfective gan 2 and perfective zo2-occur in the postverbal position, affording the creation of well-matched pairs. All the sentences were audio-recorded for computer presentation. The mean lengths of the audio stimuli were $1,461 \mathrm{msec}(S D=156)$ and $1,652 \mathrm{msec}$ $(S D=166)$, respectively, for utterances with activity and accomplishment verbs $[t(78)=-5.255, p<.001] .4$ The full set of stimu- lus sentences may be downloaded from mc.psychonomic-journals .org/content/supplemental.

A pair of pictures was drawn to correspond with each sentence used in the experiment. One picture depicted the ongoing phase of the event described in the sentence, and another picture depicted the completed phase of the event (see the Appendix for sample pictures). For each picture depicting an activity verb, an agent was engaging in an action without a clear endpoint focus (e.g., a man riding a horse, a boy hiking in the hills, a girl listening to music). For each picture denoting an accomplishment verb, an agent was engaging in an action with a natural endpoint (e.g., a man eating an apple, a mother baking a cake, a grandmother knitting a sweater).

A picture-rating test was carried out to ensure that each picture pair used in the experiment adequately represented contrastive temporal phases - that is, ongoing action versus completed action. Pictures representing activity verbs and accomplishment verbs were rated by 21 university undergraduate students, all of whom were native speakers of Cantonese, using a 7-point scale, with 1 denoting a strong sense of event ongoingness and 7 denoting a strong sense of event completion. The mean picture rating score for the activity pictures representing ongoing action was $1.72(S D=0.35)$, whereas the mean picture rating score for activity pictures representing completed action was $6.15(S D=0.56)$. The mean picture-rating scores for the accomplishment pictures representing ongoing action and completed action were $1.69(S D=0.37)$ and $5.93(S D=0.69)$, respectively. Aspectual contrast in terms of ongoing versus completed focus of an event depicted in each picture pair was significant $(p<.001)$.

In this experiment, four stimuli sets were created to counterbalance the grammatical aspect (imperfective vs. perfective) of each sentence and the position of the correct pictures (left vs. right). In each stimulus set, half of the sentences were presented with the imperfective marker gan2, and the other half of the sentences with the perfective marker zo2. Half of the correct pictures were presented on the left-hand side of the computer screen, whereas the other half were presented on the right-hand side. Both halves were also further counterbalanced to include $50 \%$ ongoing pictures and $50 \%$ completed ones. The sequence of presentation of activity and accomplishment verbs in each stimulus set was randomized. The participants were randomly assigned to only one stimulus set. Thus, for each activity or accomplishment event, a participant heard only the perfective or the imperfective version of the sentence, with the correct picture in one of the two possible positions (left vs. right).

Procedure. A forced choice sentence-picture matching task was used in this experiment. During the practice session and the experiment proper, written instructions were first displayed on the computer screen in Cantonese. The participants were asked to listen to Cantonese sentences via headphones and to judge which of two pictures best matched the sentences they had just heard. Note that the participants were not specifically told to choose "the correct picture." If the picture of their choice appeared on the left, the participants had to press the "F" key on the keyboard of the computer with the left index finger. If the picture of their choice appeared on the right, the participants had to press the " $\mathrm{J}$ " key with the right index finger. Figure 1 highlights the sequence of sentence and picture presentation.

The interstimulus interval between the offset of utterance and onset of pictures was $0 \mathrm{msec}$. The pictures remained on the computer screen for a maximum of $3 \mathrm{sec}$. Failure to respond within $3 \mathrm{sec}$ was regarded as an incorrect response. For RTs, only those with matched responses were analyzed. Ongoing pictures were considered matched responses for imperfective sentences, whereas completed pictures were considered matched responses for perfective sentences. We compared both the accuracy rates and the mean RTs of the perfective and imperfective sentences. RTs were recorded using DMDX software (Forster \& Forster, 2003). Mean RTs were compared across matched perfectives and matched imperfectives, and the significance was tested using a two-way repeated measures ANOVA, with two levels of lexical aspect (accomplishment and ac- 
A. Presentation of either a perfective or imperfective sentence (auditory form):

go3 naam4zai2 taan4gan2 kam4
$\mathrm{CL}$ boy play-IMP piano
"The boy is playing the piano."

B. Presentation of a pair of pictures depicting ongoing versus completed events:
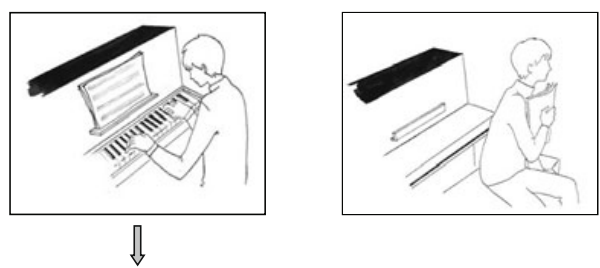

C. Decision of which picture matches the utterance by pressing a corresponding key on the computer keyboard.

Figure 1. Sentence-picture matching task.

tivity) and two levels of grammatical aspect (imperfective marker gan2 and perfective marker $z o 2$ ) as within-subjects factors.

\section{Results}

Five items with low accuracy rates (one item in activity and four items in accomplishment verbs) were excluded from further analysis. A subject analysis on accuracy rates revealed that the effect of grammatical aspect was not significant $\left[F_{1}(1,82)=2.325, p=.131\right]$. The accuracy rates for the imperfective and perfective sentences were $95.9 \%$ $(S E=0.5)$ and $96.9 \%(S E=0.6)$, respectively. The effect of lexical aspect was significant $\left[F_{1}(1,82)=5.171, p=\right.$ $.026]$. The accuracy rates for activity and accomplishment sentences were $97.2 \%(S E=0.5)$ and $95.7 \%(S E=0.6)$, respectively. The interaction between lexical aspect and grammatical aspect was significant $\left[F_{1}(1,82)=17.328\right.$, $p<.001]$. An item analysis revealed no significant effect for grammatical aspect $\left[F_{2}(1,15)=1.910, p=.187\right.$; accuracy rates for the imperfective and perfective sentences were $95.6 \%(S E=0.9)$ and $96.9 \%(S E=0.5)$, respectively] or for lexical aspect $\left[F_{2}(1,15)=2.971, p=\right.$ .105 ; accuracy rates for the activity and accomplishment sentences were 97.0\% $(S E=0.7)$ and $95.5 \%(S E=0.7)$, respectively]. However, the interaction between lexical aspect and grammatical aspect was significant $\left[F_{2}(1,15)=\right.$ $9.010, p=.009]$. Table 2 shows the accuracy rates for matched perfectives and matched imperfectives in each condition. As can be seen in Table 2, the accuracy rates for matched imperfectives were slightly higher than those for matched perfectives for the activity sentences, both in the subject analysis $[t(82)=-2.223, p=.029]$ and in the item analysis $[t(18)=-2.182, p=.043]$. For the accomplishment sentences, the accuracy rates showed reverse facilitation, with matched perfectives being slightly higher than matched imperfectives, both in the subject analysis $[t(82)=3.958, p<.001]$ and in the item analysis $[t(15)=2.681, p=.017]$. These accuracy rates show that the participants were more sensitive to imperfective cues when processing activity verbs, whereas they were more sensitive to perfective cues when processing accomplishment verbs.

The mean RTs for matched perfectives and matched imperfectives in each condition are shown in Table 3. A subject analysis revealed that the effect of grammatical aspect was significant $\left[F_{1}(1,82)=12.700, p=.001\right]$. The mean RTs for the imperfective and perfective sentences were $1,028 \mathrm{msec}(S E=20)$ and $1,062 \mathrm{msec}(S E=21)$, respectively. The effect of lexical aspect was significant $\left[F_{1}(1,82)=5.887, p=.017\right]$. The mean RTs for activity and accomplishment sentences were $1,033 \mathrm{msec}(S E=$ $20)$ and $1,056 \mathrm{msec}(S E=21)$, respectively. The interaction between lexical aspect and grammatical aspect was significant $\left[F_{1}(1,82)=76.301, p<.001\right]$. An item analysis revealed no significant effect for grammatical aspect $\left[F_{2}(1,15)=1.227, p=.285\right.$; mean RTs for the imperfective and perfective sentences were $1,039 \mathrm{msec}(S E=25)$

Table 2

Mean Accuracy Rates (in Percentages) for Matched Perfectives and Matched Imperfectives in a Sentence-Picture Matching Task

\begin{tabular}{|c|c|c|c|c|c|}
\hline \multirow{3}{*}{$\begin{array}{c}\text { Type of } \\
\text { Analysis }\end{array}$} & \multirow{3}{*}{$\begin{array}{c}\text { Grammatical } \\
\text { Aspect }\end{array}$} & \multicolumn{4}{|c|}{ Lexical Aspect (Verb Type) } \\
\hline & & \multicolumn{2}{|c|}{ ACT } & \multicolumn{2}{|c|}{$\mathrm{ACC}$} \\
\hline & & $M$ & $S D$ & $M$ & $S D$ \\
\hline \multirow[t]{2}{*}{ Subject analysis } & Perfective & 96.1 & 8.4 & 97.8 & 5.6 \\
\hline & Imperfective & 98.2 & 3.9 & 93.5 & 8.3 \\
\hline \multirow[t]{2}{*}{ Item analysis } & Perfective & 96.1 & 3.5 & 97.8 & 3.0 \\
\hline & Imperfective & 98.2 & 3.4 & 93.3 & 5.4 \\
\hline
\end{tabular}

Note-Perfective facilitation for accomplishments and imperfective facilitation for activities (for both subject and item analyses), $p<.05$. ACT, activity; ACC, accomplishment. 
Table 3

Mean Response Times (in Milliseconds) for Matched Perfectives and Matched Imperfectives in a Sentence-Picture Matching Task

\begin{tabular}{|c|c|c|c|c|c|}
\hline \multirow{3}{*}{$\begin{array}{c}\text { Type of } \\
\text { Analysis }\end{array}$} & \multirow{3}{*}{$\begin{array}{c}\text { Grammatical } \\
\text { Aspect }\end{array}$} & \multicolumn{4}{|c|}{ Lexical Aspect (Verb Type) } \\
\hline & & \multicolumn{2}{|c|}{ ACT } & \multicolumn{2}{|c|}{$\mathrm{ACC}$} \\
\hline & & $M$ & $S D$ & $M$ & $S D$ \\
\hline \multirow{2}{*}{ Subject analysis } & Perfective & 1,086 & 198 & 1,037 & 193 \\
\hline & Imperfective & 980 & 172 & 1,076 & 210 \\
\hline \multirow[t]{2}{*}{ Item analysis } & Perfective & 1,084 & 118 & 1,036 & 8 \\
\hline & Imperfective & 988 & 145 & 1,089 & 10 \\
\hline
\end{tabular}

Note-Interaction effect between lexical and grammatical aspect (for both subject and item analyses), $p<.001$. ACT, activity; ACC, accomplishment.

and $1,060 \mathrm{msec}(S E=22)$, respectively] or for lexical aspect $\left[F_{2}(1,15)=0.889, p=.361\right.$; mean RTs for the activity and accomplishment sentences were $1,036 \mathrm{msec}$ $(S E=30)$ and $1,063 \mathrm{msec}(S E=20)$, respectively $]$. However, the interaction between lexical aspect and grammatical aspect was significant $\left[F_{2}(1,15)=19.109\right.$, $p=.001]$. As can be seen in Table 3 , the mean RTs for matched imperfectives were slightly faster than those for matched perfectives for the activity sentences, both in the subject analysis $[t(82)=-10.476, p<.001]$ and in the item analysis $[t(18)=-4.742, p<.001]$. For the accomplishment sentences, the mean RT showed reverse facilitation, with responses for matched perfectives being slightly faster than those for matched imperfectives, both in the subject analysis $[t(82)=2.688, p=.009]$ and in the item analysis $[t(15)=2.053, p=.058]$. These RTs show that the participants were more sensitive to certain combinations between lexical and grammatical aspect than to others. More specifically, they responded more quickly to imperfective-activity combinations than to perfectiveactivity combinations, and conversely, there was also a marginal tendency for them to respond more quickly to perfective-accomplishment than to imperfectiveaccomplishment combinations.

\section{Discussion}

In this study, we set out to investigate the effect of lexical aspect on the processing of grammatical aspect. Previous studies showed patterns of aspectual processing asymmetries, but they failed to consider how different verb types might differentially impact these asymmetric patterns. Our study showed that, in terms of accuracy rate and processing speed, both perfective facilitation and imperfective facilitation may occur in sentence-picture matching tasks. More important, perfective facilitation was found with accomplishment verbs, whereas imperfective facilitation was found with activity verbs. This indicates that lexical aspect (i.e., verb type, such as accomplishment or activity) contributes to aspectual asymmetries in language processing and, as such, plays an important role in the formation of variations in the mental representation of events.

Previous studies (e.g., Chan et al., 2004; Madden \& Zwaan, 2003; Yap et al., 2004; Yap et al., 2006) have pointed out a close relationship between perfective facilitation and telicity effects. The implications of these stud- ies, which focused on accomplishment verbs only, were that the human mind converges on a mental representation more readily in the presence of a perfective aspect marker - in large part, because perfective markers encode a telic (i.e., endpoint) interpretation. Following this line of thinking, noticeably longer RTs for imperfective accomplishment sentences could then be interpreted as slower simulations and slower convergence upon a mental representation of the event, attributed in part to the fact that imperfective markers typically allow internal access to events, which could then prolong cognitive processing due to their focus on other aspects of the event, such as location, agent, and instrument (Madden \& Zwaan, 2003; see also Ferretti et al., 2007). However, although telicity may account for perfective facilitation with accomplishment verbs, it cannot explain why there is imperfective facilitation with activity verbs.

The results of the present study on Cantonese indicate that a more fundamental principle may be at work. The findings reveal that perfective facilitation obtains when the inherent telicity found in accomplishment verbs is matched by the boundedness or completedness feature of perfective markers, whereas imperfective facilitation obtains when the inherent durativity of activity verbs is matched by the ongoingness feature of imperfective markers. The principle underlying these two opposite facilitation effects appears to be a relatively simple one: Like reinforces like. That is, similar features reinforce each other. At the same time, dissimilar features have a dampening effect on each other. Thus, we see slower responses in otherwise cross-matched combinations. This simple principle underlies the perfective facilitation observed in Madden and Zwaan's (2003) study on accomplishment verbs (which are telic) and similarly underlies the imperfective facilitation observed among activity verbs (which are atelic) in the present study on Cantonese.

This same principle may underlie the aspectual asymmetries found in language acquisition and language use discussed above. As has been reported in the child language acquisition literature (e.g., Aksu-Koç, 1988, 1998; Antinucci \& Miller, 1976; Bronckart \& Sinclair, 1973; Li \& Shirai, 2000; Shirai, 1998; Shirai \& Andersen, 1995; see also Tomasello, 2003, pp. 217-224, for a summary), perfective marking is first associated with telic verbs, which include accomplishment verbs, whereas imperfective marking is first associated with atelic verbs. In particular, progressive (i.e., dynamic imperfective) marking is strongly associated with activity verbs. In terms of language use, previous studies (e.g., Brown, 1973; Comrie, 1976) have reported more frequent associations between imperfective marker + activity verb and ongoing situation than with other feature combinations (e.g., perfective marker + activity verb, which generally denotes termination of an event).

Within the framework of Barsalou's (1999) perceptual theory of knowledge, perceptual input (including linguistic input, such as aspectual information) contributes to the formation of situation models as follows. Each perceptual input activates a configuration of neurons and leaves 
a trace of these neuronal activations, which is encoded in memory as a perceptual symbol. Perceptual symbols interact with each other, particularly in associative areas of the brain, and can give rise to complex cognitive processes. Manipulations of perceptual symbols can support hierarchical representations of knowledge, giving rise to symbolic-style logical thinking and inferential thought. Not only can perceptual symbols contribute to the formation of situation models in bottom-up fashion, they also can do so in top-down fashion. Top-down processing happens, for example, when perceptual symbols influence the interpretation of new incoming perceptual input.

Within this framework of perceptual symbols, a sentence will activate a dynamic series of neural configurations that give rise to a situation model of the concept represented by the sentence, including the temporal information conveyed by its verb type (e.g., activity or accomplishment). The additional presence of a grammatical aspect marker (e.g., progressive imperfective gan 2 or perfective zo2 in Cantonese) also activates its own neural activation configuration, which will interact with the neural configuration of the verb type (i.e., lexical aspect). Together, they produce a nuanced temporal characterization of the situation being described in the sentence. Neural activations that reinforce each other are processed more rapidly - hence, the aspectual facilitations observed for imperfective-activity combinations and perfectiveaccomplishment combinations in this study.

Within the perceptual symbol framework, frequent coactivations of neural configurations also give rise to stronger connectivity (Hebbian style), which, in turn, also facilitates processing speed. More important, as was suggested in Barsalou (1999), frequent associations can give rise to symbols that can serve as attention-attuning devices. They contribute to top-down processing, particularly in associative areas in the brain. Of the two types of aspect examined in this study, grammatical aspect markers (perfective and imperfective) serve the more symbolic function, each attuning attention in working memory on certain temporal profiles of the situation depicted by the verb types (whether activity or accomplishment).

Viewed from a language evolution perspective, the more symbolic status of grammatical aspect markers emerges from a diachronic process of grammaticalization (e.g., Bybee, Perkins, \& Pagliuca, 1994; Hopper \& Traugott, 2003), whereby certain verbs with high-frequency usage become bleached of much of their original lexical meaning (in large part, due to metonymic and metaphorical extension), retaining mostly some core temporal features such as ongoingness (imperfective) or boundedness/completedness (perfective). As these verbs become semantically light, they begin to be attached to other verbs to highlight certain temporal characteristics of the situation. In time, these light verbs evolve into dedicated grammatical aspect markers, with the top-down symbolic function of attuning attention in working memory to certain temporal interpretations (e.g., ongoing focus or endpoint focus).

Lexical aspect, which refers to temporal features residing in each verb, is still strongly linked to other semantic features within the verb and, in this sense, behaves more like perceptual input in bottom-up processing, whereas grammatical aspect behaves more like symbols in topdown processing. Although each grammatical aspect marker shows its own temporal bias (e.g., ongoing focus for imperfective aspect vs. endpoint focus for perfective aspect), interaction with different verb types (i.e., lexical aspect) yields subtle differences in neural activations, giving rise to variations in temporal aspectual interpretations. In addition, the consistency of temporal aspectual information afforded by the more symbolic grammatical aspect markers contributes to their salience, interpretable as stronger neural configurations. Their salience is further enhanced in interaction environments with compatible neural configurations (e.g., imperfective-activity neural activations and perfective-accomplishment neural activations). As was noted earlier, compatibility leads to faster cognitive processing. The resultant biases in salience and processing speed appear to underlie the aspectual asymmetries observed in language acquisition literature and may also be exploited in discourse processing, further impacting frequency distributions in language use.

To summarize, our study contributes to an increasing body of literature on the mental representation and integration of lexical and grammatical information in sentence processing. It does so by considering the effect of lexical aspect on the processing of grammatical aspect and by situating the asymmetries of processing within the theoretical arguments of embodied cognition and action.

\section{AUTHOR NOTE}

This research was supported by Direct Grant 2004-06 from the Chinese University of Hong Kong and a Competitive Earmarked Research Grant (CUHK 4711H/05, Arts \& Languages) from the Research Grants Council of the Hong Kong Special Administrative Region, China (PI: F.H.Y.). We thank the editors and three anonymous reviewers for many helpful comments. Moreover, we thank the following colleagues for assistance in a series of pilot works from a crosslinguistic perspective that was crucial to the success of the present study: Grace Yi-Heng Chan, Conrad Perry, Yumi Inoue, Ying-Wai Wong, Margaret Ka-Yan Lee, Edson Miyamoto, and Seongha Rhee. We also gratefully acknowledge Lai Chim Chow for technical assistance; Irene Lam for voice recording; Calvin Chan and Kimmee Lo for picture drawing; the students, teachers, and principals of the high schools participating in our experiments; and Him Cheung, Yingchun Du, and John Zhang for valuable comments. Finally, we dedicate this article to the memory of Roger W. Andersen (1940-2008), who has taught us much about lexical and grammatical aspect in discourse, acquisition, and crosslinguistic variation, and who always had time to spare for others-including us, his students, his colleagues, and his friends. Correspondence concerning this article should be addressed to F. H. Yap, Chinese University of Hong Kong, Fung King Hey Building, Room 303A, Shatin, Hong Kong, China (e-mail: foong_ha_yap@cuhk .edu.hk).

\section{REFERENCES}

AKsu-Koç, A. (1988). The acquisition of aspect and modality: The case of past reference in Turkish. Cambridge: Cambridge University Press.

AKSU-Koç, A. (1998). The role of input vs. universal predispositions in the emergence of tense-aspect morphology: Evidence from Turkish. First Language, 18, 255-280. doi:10.1177/014272379801805402

ANDERSEN, R. W. (1991). Developmental sequences: The emergence of aspect marking in second language acquisition. In T. Huebner \& C. A. Ferguson (Eds.), Crosscurrents in second language acquisition and linguistic theories (pp. 305-324). Amsterdam: Benjamins. 
Andersen, R. W., \& ShIRAI, Y. (1994). Discourse motivations for some cognitive acquisition principles. Studies in Second Language Acquisition, 16, 133-156. doi:10.1017/S027226310001281X

Andersen, R. W., \& Shirai, Y. (1996). Primacy of aspect in first and second language acquisition: The pidgin/creole connection. In W. C. Ritchie \& T. K. Bhatia (Eds.), Handbook of second language acquisition (pp. 527-570). San Diego: Academic Press.

Antinucci, F., \& Miller, R. (1976). How children talk about what happened. Journal of Child Language, 3, 169-189. doi:10.1017/ S0305000900001434

Barsalou, L. W. (1999). Perceptual symbol systems. Behavioral \& Brain Sciences, 22, 577-660. doi:10.1017/S0140525X99002149

Bronckart, J. P., \& Sinclair, H. (1973). Time, tense and aspect. Cognition, 2, 107-130. doi:10.1016/0010-0277(72)90032-7

Brown, R. W. (1973). A first language: The early stages. Cambridge, MA: Harvard University Press.

Bybee, J., Perkins, R., \& PAGLiUCA, W. (1994). The evolution of grammar: Tense, aspect, and modality in the languages of the world. Chicago: University of Chicago Press.

Carreiras, M., Carriedo, N., Alonso, M. A., \& Fernández, A. (1997). The role of verb tense and verb aspect in the foregrounding of information during reading. Memory \& Cognition, 25, 438-446.

Chan, Y. H., Yap, F. H., Shirai, Y., \& Matthews, S. (2004). A perfective-imperfective asymmetry in language processing: Evidence from Cantonese. In S.-F. Huang (Ed.), Proceedings of the 9th International Symposium on Chinese Languages and Linguistics (pp. 383391). Taipei: National Taiwan University, Academia Sinica and the Graduate Institute of Linguistics.

Chen, J., \& ShIRAI, Y. (in press). The development of aspectual marking in child Mandarin Chinese. Applied Psycholinguistics.

CHOR, O. W. W. (2004). A semantic and pragmatic analysis of verbal particles in Cantonese. Unpublished master's thesis, University of Hong Kong.

Comrie, B. (1976). Aspect: An introduction to the study of verbal aspect and related problems. Cambridge: Cambridge University Press.

Ferretti, T. R., Kutas, M., \& McRae, K. (2007). Verb aspect and the activation of event knowledge. Journal of Experimental Psychology: Learning, Memory, \& Cognition, 33, 182-196. doi:10.1037/0278 $-7393.33 .1 .182$

Forster, K. I., \& Forster, J. C. (2003). DMDX: A Windows display program with millisecond accuracy. Behavior Research Methods, Instruments, \& Computers, 35, 116-124.

GIVón, T. (1992). The grammar of referential coherence as mental processing instructions. Linguistics, 30, 5-55.

HopPer, P. J. (1979). Aspect and foregrounding in discourse. In T. Givón (Ed.), Syntax and semantics: Vol. 12. Discourse and syntax (pp. 213241). New York: Academic Press.

Hopper, P. J., \& Traugott, E. C. (2003). Grammaticalization (2nd ed.). Cambridge: Cambridge University Press.

LI, P., \& ShIRAI, Y. (2000). The acquisition of lexical and grammatical aspect. Berlin: Mouton de Gruyter.

MADDEN, C. J., \& ZWAAN, R. A. (2003). How does verb aspect constrain event representations? Memory \& Cognition, 31, 663-672.

Magliano, J. P., \& Schleich, M. C. (2000). Verb aspect and situation models. Discourse Processes, 29, 83-112. doi:10.1207/ S15326950dp2902_1

Matthews, S., \& YIP, V. (1994). Cantonese: A comprehensive grammar. London: Routledge.
Morrow, D. G. (1985). Prepositions and verb aspect in narrative understanding. Journal of Memory \& Language, 24, 390-404. doi:10.1016/ 0749-596X(85)90036-1

Morrow, D. G. (1990). Spatial models, prepositions, and verb-aspect markers. Discourse Processes, 13, 441-469.

ShIRAI, Y. (1998). The emergence of tense-aspect morphology in Japanese: Universal predisposition? First Language, 18, 281-309. doi:10.1177/014272379801805403

ShirAi, Y., \& ANDERSEN, R. W. (1995). The acquisition of tense-aspect morphology: A prototype account. Language, 71, 743-762.

Sмiтн, C. (1997). The parameter of aspect (2nd ed.). Dordrecht: Kluwer.

Tomasello, M. (2003). Constructing a language: A usage-based theory of language acquisition. Cambridge, MA: Harvard University Press.

Vendler, Z. (1967). Linguistics in philosophy. Ithaca, NY: Cornell University Press.

Yap, F. H., Chan, Y. H., Shirai, Y., Tan, L. H., Matthews, S., \& Li, P. (2004, August). A perfective-imperfective asymmetry in the human mind: Evidence from Cantonese and Mandarin. Paper presented the 28th International Congress of Psychology, Beijing.

Yap, F. H., Inoue, Y., Shirai, Y., Matthews, S., Wong, Y. W., \& Chan, Y. H. (2006). Aspectual asymmetries in Japanese: Evidence from a reaction time study. In T. Vance (Ed.), Japanese/Korean linguistics (Vol. 14, pp. 113-124). Stanford, CA: CSLI Publications.

ZWAan, R. A., \& RADVANSKy, G. A. (1998). Situation models in language comprehension and memory. Psychological Bulletin, 123, 162185. doi:10.1037/0033-2909.123.2.162

\section{NOTES}

1. In Cantonese romanization, numerals represent tones. Cantonese is said to have as many as nine distinctive tones, although most modern reference grammars (particularly those for Hong Kong Cantonese) use a standard range of only six tones (e.g., Matthews \& Yip, 1994).

2. Whereas visual stimuli were used for the English sentence presentations, auditory stimuli were used in the Cantonese study. Ongoing studies in Cantonese using the visual modality (i.e., written sentences instead of auditory stimuli) yielded similar results.

3. These lexical aspect categories are often distinguished on the basis of a set of operational tests (e.g., Chen \& Shirai, in press, in Mandarin Chinese; Shirai \& Andersen, 1995, in English). We modified these tests and applied them to Cantonese to classify verbs into activity verbs and accomplishment verbs. To distinguish between activity and accomplishment verbs, we used the following test from Vendler (1967): "If you stop in the middle of the action, have you done the action?" If the answer is $y e s$, the verb in question is an activity; if the answer is no, the verb is an accomplishment.

4. Although the difference in length between activity and accomplishment sentences was significant, this did not compromise our findings, given that there was crossover interaction, in which, among activity verbs, there was faster processing with imperfectives than with perfectives, whereas among accomplishment verbs, there was faster processing in the reverse direction.

\section{SUPPLEMENTAL MATERIALS}

The sentence stimuli from this article may be downloaded from mc.psychonomic-journals.org/content/supplemental. 


\section{APPENDIX A}

Pair of Pictures Using an Activity Verb

A

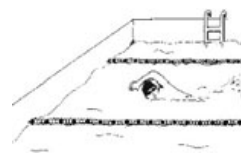

go4go1 jau4gan2 seoi2 older brother swim-IMPF water 'Brother is swimming.'
B

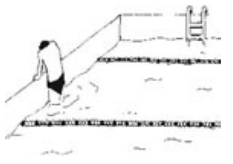

go4go1 jau4zo2 seoi2

older brother swim-PERF water 'Brother has swum.'

APPENDIX B

Pair of Pictures Using an Accomplishment Verb

A

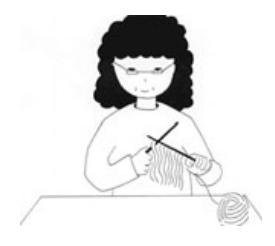

po4po2 zik1gan2 gin6 laang1saam1 grandma knit-IMPF CL sweater 'Grandma is knitting a sweater.'
B

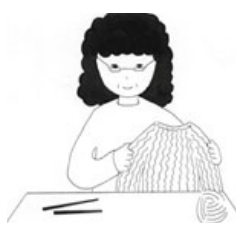

po4po2 zik1zo2 gin6laang1saam1 grandma knit-PERF CL sweater 'Grandma has knitted a sweater.'

(Manuscript received March 28, 2007;

revision accepted for publication February 4, 2009.) 